\title{
AI DRIVEN OCR: RESOLVING HANDWRITTEN FONTS RECOGNIZABILITY PROBLEMS
}

\author{
Diana Bratić (iD), Nikolina Stanić Loknar \\ University of Zagreb, Faculty of Graphic Arts, Zagreb, Croatia
}

\begin{abstract}
Optical Character Recognition (OCR) is the electronic or mechanical conversion of images of typed, handwritten, or printed text into machine-encoded text. Advanced systems are capable to produce a high degree of recognition accuracy for most technic fonts, but when it comes to handwritten forms there is a problem occur in recognizing certain characters and limitations with conventional OCR processes persist. It is most pronounced in ascenders $(k, b, l, d, h, t)$ and descenders $(g, j, p, q, y)$. If the characters are linked by ligatures, the ascending and descending strokes are even less recognizable to the scanners. In order to reduce the likelihood of a recognition error, it is a necessary to create a large database of stored characters and their glyphs. Feature extraction decomposes glyphs into features like lines, closed loops, line direction, and line intersections. A Multilayer Perceptron (MLP) neural network based on Back Propagation Neural Network (BPNN) algorithm as a method of Artificial Intelligence (Al) has been used in text identification, classification and recognition using various methods: image pattern based, text-based, mark-based etc. Also, the application of Al generates of a large database of different letter cuts, and modifications, and variation of the same letter character structure. For this purpose, the recognizability test of handwritten fonts was performed. Within main group, subgroups of independent letter characters and letter characters linked by ligatures are created, and reading errors were observed. In each subgroup, four different font families (bold stroke, alternating stroke, monoline stroke, and brush stroke) were tested. In subgroup of independent letter characters, errors were observed in similar rounded lines such as the characters a, and e. In the subgroup of letter characters linked by ligatures, errors were also observed in similar rounded lines such as the letter characters $a$ and $e, m$ and $n$, but also in ascenders $b$ and $I$, and descenders $g$ and $q$. Furthermore, seven letter cuts were made from each basic test letters, and up to are thin, ultra-light, light, regular, semi-bold, bold, and ultra-bold, and stored in the existing EMNIST database. The scanning test was repeated, and recently obtained results showed a decrease in the deviation rate, i.e. higher accuracy. Reducing the number of deviations shows that the neural network gives acceptable answers but requires creation of a larger database within about 56,000 different characters.
\end{abstract}

Key words: OCR, handwritten font, letter character, artificial intelligence, MLP BPNN arhitecture

\section{INTRODUCTION}

Handwritten script typefaces are based upon the varied and often fluid stroke created by handwriting or software. Thanks to the available digital technology, there are countless variants of handwritten fonts today. Because of their diversity, the are interesting to designers and are increasingly used. However, the problem arises with their optical readability and recognizability. Handwriting recognition is ability of a computer to receive and interpret intelligible handwritten input from different sources (Grzelak et al, 2019).

Many authors point to the problem of recognizability of handwritten fonts or some specific letter characters significant for certain languages and try to offer different Al solutions for problem resolving.

Rao and his team (2016) in their study presents a modified back propagation-based method for optical character recognition. Authors in their proposed method successfully computes error rate with promising accuracy of $100 \%$ OCR.

Phangtriastu, Harefa and Tanoto (2017) uses several techniques as a comparison for some extracted features, such as zoning algorithm, projection profile, Histogram of Oriented Gradients (HOG) and combination of those feature extractions. Their experiment achieves the highest accuracy of $94.43 \%$.

Desai, Bhavikatti and Patil (2013) proposed approach for handwriting recognition system processing, segmentation, and feature extraction with neural network for character recognition with $99.9 \%$ accuracy for separate character written documents, and $70-80 \%$ accuracy for handwriting text.

Maitra, Bhattacharya and Parui (2015) described Convolutional Neural Network (CNN) based common approach to handwritten character recognition of multiple scripts with accuracy between 95.6 and $99.1 \%$. Also, Zheng, Iwana and Uchida (2019) explained a mining the displacement of max pooling for text 
recognition. D'Souza and Mascarenhas in their paper (2018) proposed an idea to recognize offline Handwritten Mathematical Expression and symbols (HME) using CNN for classification.

Driss et al. (2017) made a comparison study between MLP and Convolutional Neural Network models for character recognition.

As can be seen from a brief overview of the researches, an Artificial Neural Network (ANN) is commonly used for searching for dependencies between data that are not in a linear correlation, and yet can be combined into one complex input set. Generally, a network processes a set of input data in parallel, and different priorities and assigned to these values, which can be changed and processed differently according to a specific scheme during learning (Grzelak et al, 2019).

The main goal of this research was to determinate AI driven OCR system effectiveness in recognizability of handwritten fonts. The research was based of adding two main sets of letters in existing the EMNIST dataset of letters.

To the purpose of this research a Multilayer Perceptron (MLP) neural network based on Back Propagation Neural Network (BPNN) algorithm has been used. MLP is a class of feedforward artificial neural network (ANN). An MLP consist of at least three layers of nodes: an input layer, a hidden layer, and an output layer. Except for the input nodes, each node is a neuron that uses a nonlinear activation function.

The results obtained from the experiment are summarized and presented with concluding remarks and recommendations for further research.

\section{METHODS}

In order to make the methodology of making this paper clearer, the basic concepts related to typography will be briefly explained.

Classification in typography is very important for easier navigation in many different letter cuts, so the letters are divided into several basic forms.

A certain stylization of a letter is called a letter cut. The letter cut is classified as thin, ultra-light, light, regular, semi-bold, bold, and ultra-bold according to the ration of whiteness and blackness.

In letter characters, common forms can be found, i.e. elements that form one letter character. Different letter characters have different element connections, and the basic move, ascending line or move, and descending line or move are some of them. Ascender or ascending move is the part on the current letters $k, b, l, d, h, t$ that rises above the line defined by the current letters $a, c, e, m, n$, etc. A descender of descending stroke is a part of a letter character that descends below the basic letter line (e.g. g, j, p, q, y).

Only handwritten forms will be used in this paper due to their anatomy which is a problem in optical character recognition.

This research was carried out using artificial neural network and machine learning. For this purpose, was used the EMNIST dataset of letters (Cohen et al, 2017). In first step specific dataset of different examples of handwriting test photos is defined. This dataset consists set of English letter characters from A to Z. It contains separated letter characters for every font type of each test group.

Within the group of handwritten forms, two subgroups of fonts were created, namely independent letter characters and letter characters linked by ligatures. Furthermore, four types of font families were created in each basic cut group: bold stroke, alternating stroke, monoline stroke, and brush stroke. Finally, seven letter cuts were made for each of the four font families: thin, ultra-light, light, regular, semi-bold, bold, and ultra-bold. Thus, for testing for each group, 28 fonts were made, i.e. 56 overall. All tested fonts are made by software Fontographer 5.2.

New created letter characters have been added to existing the EMNIST dataset, and using MLP BPNN architecture, the effectiveness of recognition of added characters in the prepared dataset was measured. All calculations were made in Statistica 13.5.0.17.

\subsection{Handwritten fonts with independent letter characters}

First subgroup of tested fonts was handwritten independent letter characters in four basic font families (bold stroke, alternating stroke, monoline stroke, and brush stroke) (Table 1). 
Table 1: An overview of handwritten fonts with independent letter characters

\begin{tabular}{|l|l|l|l|l|}
\hline & \multicolumn{1}{|c|}{ Bold stroke } & \multicolumn{1}{|c|}{ Alternating stroke } & \multicolumn{1}{|c|}{ Monoline stroke } & \multicolumn{1}{c|}{ Brush stroke } \\
\hline Thin cut & Tangerine Thin & Modeschrift Thin & Daily Life Thin & Konichiwa Thin \\
\hline Ultra-Light cut & $\begin{array}{l}\text { Tangerine Ultra- } \\
\text { Light }\end{array}$ & $\begin{array}{l}\text { Modeschrift Ultra- } \\
\text { Light }\end{array}$ & $\begin{array}{l}\text { Daily Life Ultra- } \\
\text { Light }\end{array}$ & $\begin{array}{l}\text { Konichiwa Ultra- } \\
\text { Light }\end{array}$ \\
\hline Light cut & Tangerine Light & Modeschrift Light & Daily Life Light & Konichiwa Light \\
\hline Regular cut & Tangerine Regular & $\begin{array}{l}\text { Modeschrift } \\
\text { Regular }\end{array}$ & Daily Life Regular & Konichiwa Regular \\
\hline Semi-Bold cut & $\begin{array}{l}\text { Tangerine Semi- } \\
\text { Bold }\end{array}$ & $\begin{array}{l}\text { Modeschrift Semi- } \\
\text { Bold }\end{array}$ & Daily Life Semi-Bold & $\begin{array}{l}\text { Konichiwa Semi- } \\
\text { Bold }\end{array}$ \\
\hline Bold cut & Tangerine Bold & Modeschrift Bold & Daily Life Bold & Konichiwa Bold \\
\hline Ultra-Bold cut & $\begin{array}{l}\text { Tangerine Ultra- } \\
\text { Bold }\end{array}$ & $\begin{array}{l}\text { Modeschrift Ultra- } \\
\text { Bold }\end{array}$ & Daily Life Ultra-Bold & $\begin{array}{l}\text { Konichiwa Ultra- } \\
\text { Bold }\end{array}$ \\
\hline
\end{tabular}

Regarding list of handwritten fonts with independent letter characters, tested samples are presented in Figure 1.

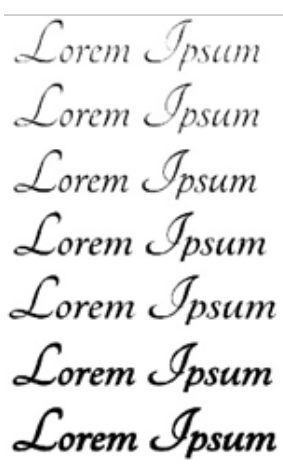

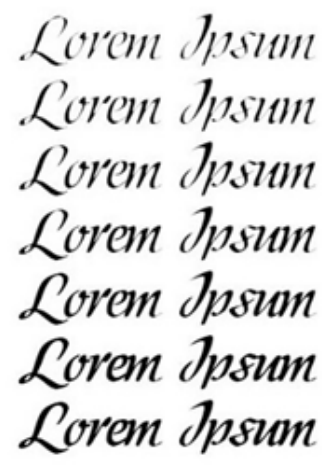

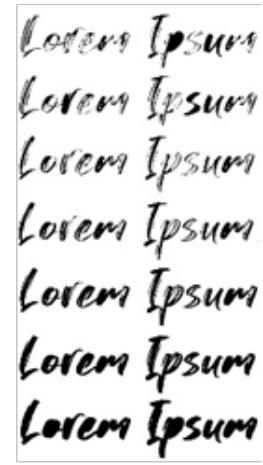

Figure 1: Sample of tested handwritten fonts with independent letter characters

\subsection{Handwritten fonts with letter characters linked by ligatures}

Second subgroup of tested fonts was handwritten letter characters linked by ligatures in four basic letter cuts (bold stroke, alternating stroke, monoline stroke, and brush stroke (Table 2).

Table 2: An overview of handwritten fonts with letter characters linked by ligatures

\begin{tabular}{|l|l|l|l|l|}
\hline & \multicolumn{1}{|c|}{ Bold stroke } & \multicolumn{1}{|c|}{ Alternating stroke } & \multicolumn{1}{|c|}{ Monoline stroke } & \multicolumn{1}{c|}{ Brush stroke } \\
\hline Thin cut & Brightlast Thin & Shelley LTS Thin & Abecedary Thin & Someone Thin \\
\hline Ultra-Light cut & Brightlast Ultra-Light & $\begin{array}{l}\text { Shelley LTS UItra- } \\
\text { Light }\end{array}$ & $\begin{array}{l}\text { Abecedary Ultra- } \\
\text { Light }\end{array}$ & $\begin{array}{l}\text { Someone Ultra- } \\
\text { Light }\end{array}$ \\
\hline Light cut & Brightlast Light & Shelley LTS Light & Abecedary Light & Someone Light \\
\hline Regular cut & Brightlast Regular & Shelley LTS Regular & Abecedary Regular & Someone Regular \\
\hline Semi-Bold cut & Brightlast Semi-Bold & $\begin{array}{l}\text { Shelley LTS Semi- } \\
\text { Bold }\end{array}$ & Abecedary Semi-Bold & $\begin{array}{l}\text { Someone Semi- } \\
\text { Bold }\end{array}$ \\
\hline Bold cut & Brightlast Bold & Shelley LTS Bold & Abecedary Bold & Someone Bold \\
\hline Ultra-Bold cut & Brightlast Ultra-Bold & $\begin{array}{l}\text { Shelley LTS Ultra- } \\
\text { Bold }\end{array}$ & $\begin{array}{l}\text { Abecedary Ultra- } \\
\text { Bold }\end{array}$ & $\begin{array}{l}\text { Someone Ultra- } \\
\text { Bold }\end{array}$ \\
\hline
\end{tabular}

Regarding list of handwritten fonts with letter characters linked by ligatures, tested samples are presented in Figure 2. 

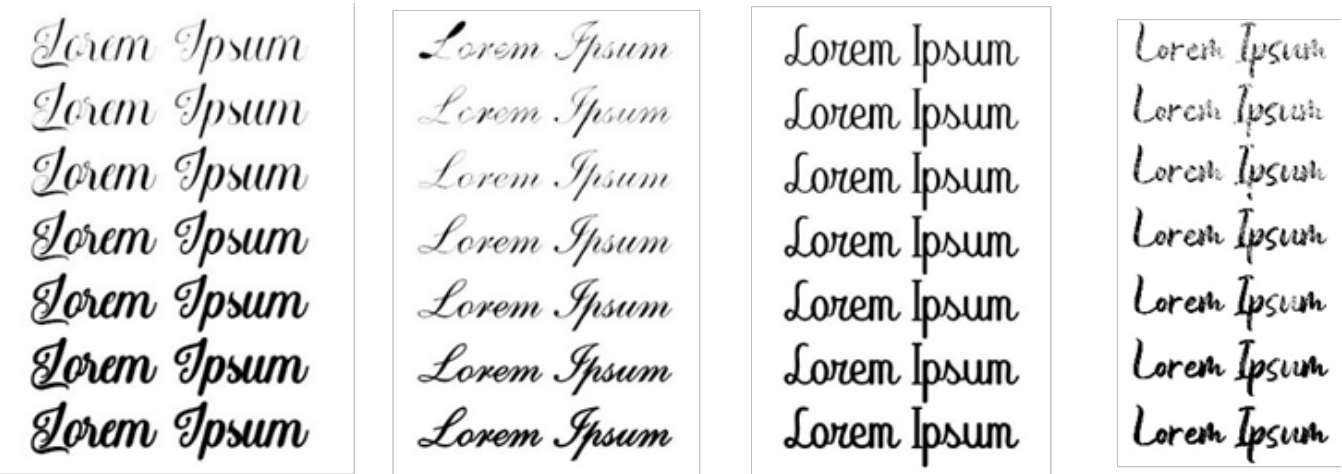

Figure 2: Sample of tested handwritten fonts with letter characters linked by ligatures

\subsection{Artificial intelligence and OCR}

A Multilayer Perceptron (MLP) is a class of feedforward Artificial Neural Network (ANN) (Rao et al, 2016). An MLP consist multiple layers of perceptrons with threshold activation, i.e. a least three layers of nodes: an input layer, a hidden layer and output layer. Except for the input nodes, each node is a neuron that uses a nonlinear activation function. MLP utilizes a supervised learning technique call Back Propagation for training.

The algorithm used in this experiment is Back Propagation Network (BPNN). This algorithm generates an appropriate model that can be used to map the output based on the input data (Jafri and Arabnia, 2009). Figure 3 shows three layers of BPNN structure for this experiment. The input features are based on the feature extraction methods. The number of hidden nodes is obtained from input features and output total classes in experiment, i.e. 56 classes.

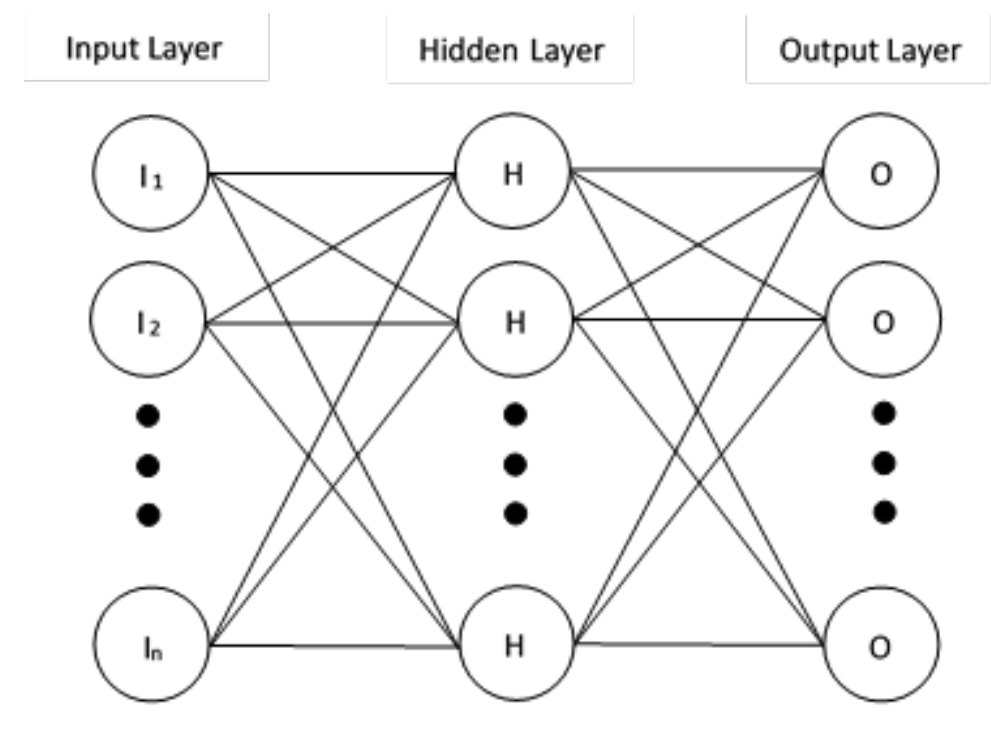

Figure 3: Architecture of Back Propagation Neural Network of experiment

The training algorithm (digital handwritten font from the EMNIST dataset) was used as a tool for training in this research. Expanded testing dataset are digital dataset of 1.456 created letter characters.

\section{RESULTS AND DISCUSSION}

This experiment used the EMNIST dataset of handwritten characters derived from the NIST Special Database 19. Original the EMNIST dataset contains several hundred thousand photos of handwritten alphanumeric characters divided in into six different subgroups.

Total images of Lorem Ipsum words that used in this experiment is 5.600, which mean 100 images for every single created font type. Both letter characters been added to the existing the EMNIST dataset and using of above described Neural Network Architecture, the effectiveness of recognition of these letter characters 
in the prepared dataset was tested. The task was to determine how the network handles the identification of handwritten letter characters in some specific order in word such as maecenas, aliquam, vulputate, fringilla, aenean, fermentum, laoreet, eleifend etc.

Table 3 shows the results of testing of first subgroup of four font families with independent letter characters in seven different letter cuts by standard OCR. The highest accuracy score is achieved by the sets of monoline stroke font family, regular cut with $94.21 \%$. Then follows bold stroke font family, semi bold cut with $93.66 \%$, alternating stroke font family, regular cut with $90.21 \%$, and brush stroke font family, semi bold cut with $87.98 \%$.

The lowest accuracy score is achieved by the sets of brush stroke family, ultra-bold cut with $84.21 \%$, than alternating stroke, thin cut with $88.43 \%$, bold stroke font family, ultra-bold cut with $90.36 \%$, and finally monoline stroke family, also ultra-bold cut with $91.63 \%$.

Table 3: Accuracy results for independent handwritten letter characters in percentage, standard OCR

\begin{tabular}{|c|c|c|c|c|c|}
\hline $\begin{array}{l}\text { Training EMNIST } \\
\text { dataset }\end{array}$ & $\begin{array}{l}\text { Expanded Testing } \\
\text { Dataset }\end{array}$ & $\begin{array}{l}\text { Bold stroke } \\
\text { (indep. } \\
\text { characters) }\end{array}$ & $\begin{array}{l}\text { Alternating } \\
\text { stroke } \\
\text { (indep. } \\
\text { characters) }\end{array}$ & $\begin{array}{l}\text { Monoline } \\
\text { stroke } \\
\text { (indep. } \\
\text { characters) }\end{array}$ & $\begin{array}{c}\text { Brush stroke } \\
\text { (indep. } \\
\text { characters) }\end{array}$ \\
\hline $\begin{array}{l}\text { Digital } \\
\text { handwritten font }\end{array}$ & $\begin{array}{l}\text { Sets of thin cut } \\
\text { Digital handwritten } \\
\text { font }\end{array}$ & $\begin{array}{l}91.92 \\
97.21\end{array}$ & $\begin{array}{l}88.43 \\
96.97\end{array}$ & $\begin{array}{l}92.76 \\
97.44\end{array}$ & $\begin{array}{l}87.22 \\
94.97\end{array}$ \\
\hline $\begin{array}{l}\text { Digital } \\
\text { handwritten font }\end{array}$ & $\begin{array}{l}\text { Sets of ultra-light cut } \\
\text { Digital handwritten } \\
\text { font }\end{array}$ & $\begin{array}{l}91.07 \\
97.72\end{array}$ & $\begin{array}{l}88.92 \\
97.51\end{array}$ & $\begin{array}{l}93.51 \\
97.98\end{array}$ & $\begin{array}{l}87.93 \\
96.58\end{array}$ \\
\hline $\begin{array}{l}\text { Digital } \\
\text { handwritten font }\end{array}$ & $\begin{array}{l}\text { Sets of light cut } \\
\text { Digital handwritten } \\
\text { font }\end{array}$ & $\begin{array}{l}91.84 \\
98.55\end{array}$ & $\begin{array}{l}89.82 \\
97.87\end{array}$ & $\begin{array}{l}93.90 \\
99.43\end{array}$ & $\begin{array}{l}88.28 \\
97.47\end{array}$ \\
\hline $\begin{array}{l}\text { Digital } \\
\text { handwritten font }\end{array}$ & $\begin{array}{l}\text { Sets of regular cut } \\
\text { Digital handwritten } \\
\text { font }\end{array}$ & $\begin{array}{l}93.01 \\
99.17\end{array}$ & $\begin{array}{l}90.21 \\
98.46\end{array}$ & $\begin{array}{l}94.21 \\
99.51\end{array}$ & $\begin{array}{l}87.52 \\
97.96\end{array}$ \\
\hline $\begin{array}{l}\text { Digital } \\
\text { handwritten font }\end{array}$ & $\begin{array}{l}\text { Sets of semi-bold cut } \\
\text { Digital handwritten } \\
\text { font }\end{array}$ & $\begin{array}{l}93.66 \\
99.12\end{array}$ & $\begin{array}{l}89.03 \\
97.98\end{array}$ & $\begin{array}{l}93.92 \\
98.22\end{array}$ & $\begin{array}{l}87.98 \\
97.01\end{array}$ \\
\hline $\begin{array}{l}\text { Digital } \\
\text { handwritten font }\end{array}$ & $\begin{array}{l}\text { Sets of bold cut } \\
\text { Digital handwritten } \\
\text { font }\end{array}$ & $\begin{array}{l}91.97 \\
97.41\end{array}$ & $\begin{array}{l}88.56 \\
96.41\end{array}$ & $\begin{array}{l}92.45 \\
98.78\end{array}$ & $\begin{array}{l}86.03 \\
96.58\end{array}$ \\
\hline $\begin{array}{l}\text { Digital } \\
\text { handwritten font }\end{array}$ & $\begin{array}{l}\text { Sets of ultra-bold cut } \\
\text { Digital handwritten } \\
\text { font }\end{array}$ & $\begin{array}{l}90.36 \\
97.02\end{array}$ & $\begin{array}{l}88.62 \\
96.22\end{array}$ & $\begin{array}{l}91.63 \\
98.08\end{array}$ & $\begin{array}{l}84.21 \\
96.92\end{array}$ \\
\hline
\end{tabular}

In Table 4 are represented the results of testing of first subgroup of four font families with independent letter characters in seven different letter cuts by AI driven OCR. The highest accuracy score is achieved by the sets of bold stroke font family, semi-bold cut with $97.92 \%$. Then follows monoline stroke font family, regular cut with $97.63 \%$, alternating stroke font family, also regular cut with $96.43 \%$, and brush stroke font family, semi-bold cut with $96.12 \%$.

The lowest accuracy is score achieved by the sets of brush stroke family, ultra-bold cut with $92.44 \%$, than alternating stroke, thin cut with $94.41 \%$, monoline stroke font family, ultra-bold cut with $95.83 \%$, and the last one is monoline stroke family, also ultra-bold cut with $95.88 \%$.

Figure 4 shows average percentage increase in recognizability of independent handwritten letter characters using Al driven OCR compared to standard OCR. The biggest increasing rate is for brush stroke font family and amounts $7.79 \%$. The smallest increasing is noted for monoline stroke font family, $3.46 \%$. Bold stroke font family records an increase rate of $4.94 \%$, and alternating stroke font family of $6.59 \%$. Average percentage for subgroup of independent handwritten characters is $5.70 \%$.

Individually speaking it is $2.35 \%$ for monoline stroke font family, regular cut, and $9.80 \%$ for brush stroke font family set, bold cut. 
Table 4: Accuracy results for independent handwritten letter characters in percentage, Al driven OCR

\begin{tabular}{|c|c|c|c|c|c|}
\hline $\begin{array}{l}\text { Training EMNIST } \\
\text { dataset }\end{array}$ & $\begin{array}{l}\text { Expanded Testing } \\
\text { Dataset }\end{array}$ & $\begin{array}{l}\text { Bold stroke } \\
\text { (indep. } \\
\text { characters) }\end{array}$ & $\begin{array}{c}\text { Alternating } \\
\text { stroke (indep. } \\
\text { characters) } \\
\end{array}$ & $\begin{array}{c}\text { Monoline } \\
\text { stroke (indep. } \\
\text { characters) }\end{array}$ & $\begin{array}{l}\text { Brush stroke } \\
\text { (indep. } \\
\text { characters) }\end{array}$ \\
\hline $\begin{array}{l}\text { Digital } \\
\text { handwritten font }\end{array}$ & $\begin{array}{l}\text { Sets of thin cut } \\
\text { Digital handwritten } \\
\text { font }\end{array}$ & $\begin{array}{l}96.52 \\
97.21\end{array}$ & $\begin{array}{l}94.41 \\
96.97\end{array}$ & $\begin{array}{l}96.02 \\
97.44\end{array}$ & $\begin{array}{l}93.98 \\
94.97\end{array}$ \\
\hline $\begin{array}{l}\text { Digital } \\
\text { handwritten font }\end{array}$ & $\begin{array}{l}\text { Sets of ultra-light cut } \\
\text { Digital handwritten } \\
\text { font }\end{array}$ & $\begin{array}{l}96.10 \\
97.72\end{array}$ & $\begin{array}{l}95.92 \\
97.51\end{array}$ & $\begin{array}{l}96.44 \\
97.98\end{array}$ & $\begin{array}{l}94.86 \\
96.58\end{array}$ \\
\hline $\begin{array}{l}\text { Digital } \\
\text { handwritten font }\end{array}$ & $\begin{array}{l}\text { Sets of light cut } \\
\text { Digital handwritten } \\
\text { font }\end{array}$ & $\begin{array}{l}97.03 \\
98.55\end{array}$ & $\begin{array}{l}96.21 \\
97.87\end{array}$ & $\begin{array}{l}97.21 \\
99.43\end{array}$ & $\begin{array}{l}95.49 \\
97.47\end{array}$ \\
\hline $\begin{array}{l}\text { Digital } \\
\text { handwritten font }\end{array}$ & $\begin{array}{l}\text { Sets of regular cut } \\
\text { Digital handwritten } \\
\text { font }\end{array}$ & $\begin{array}{l}97.89 \\
99.17\end{array}$ & $\begin{array}{l}96.43 \\
98.46\end{array}$ & $\begin{array}{l}97.63 \\
99.51\end{array}$ & $\begin{array}{l}94.99 \\
97.96\end{array}$ \\
\hline $\begin{array}{l}\text { Digital } \\
\text { handwritten font }\end{array}$ & $\begin{array}{l}\text { Sets of semi-bold cut } \\
\text { Digital handwritten } \\
\text { font }\end{array}$ & $\begin{array}{l}97.92 \\
99.12\end{array}$ & $\begin{array}{l}96.19 \\
97.98\end{array}$ & $\begin{array}{l}96.26 \\
98.22\end{array}$ & $\begin{array}{l}96.12 \\
97.01\end{array}$ \\
\hline $\begin{array}{l}\text { Digital } \\
\text { handwritten font }\end{array}$ & $\begin{array}{l}\text { Sets of bold cut } \\
\text { Digital handwritten } \\
\text { font }\end{array}$ & $\begin{array}{l}97.42 \\
97.41\end{array}$ & $\begin{array}{l}95.77 \\
96.41\end{array}$ & $\begin{array}{l}96.32 \\
98.78\end{array}$ & $\begin{array}{l}95.83 \\
96.58\end{array}$ \\
\hline $\begin{array}{l}\text { Digital } \\
\text { handwritten font }\end{array}$ & $\begin{array}{l}\text { Sets of ultra-bold cut } \\
\text { Digital handwritten } \\
\text { font }\end{array}$ & $\begin{array}{l}95.88 \\
97.02\end{array}$ & $\begin{array}{l}94.97 \\
96.22\end{array}$ & $\begin{array}{l}95.83 \\
98.08\end{array}$ & $\begin{array}{l}92.44 \\
96.92\end{array}$ \\
\hline
\end{tabular}

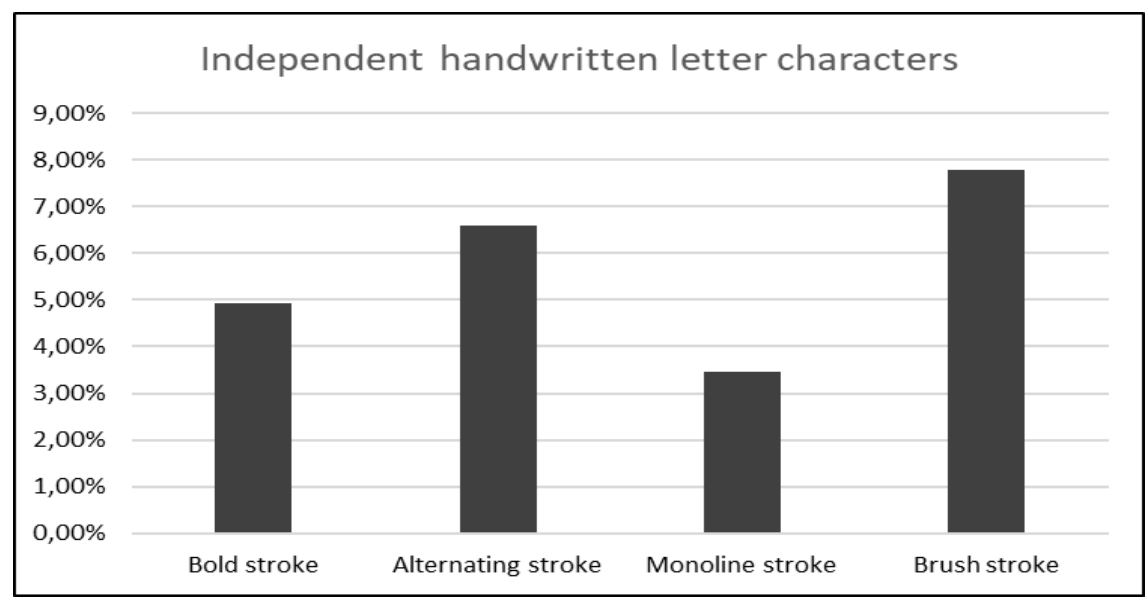

Figure 4: Average percentage increase in recognizability of independent handwritten letter characters using Al driven OCR

Table 5 gives the results of testing of second subgroup of four font families with linked letter characters in seven different letter cuts by standard OCR. The highest accuracy score here is achieved by the sets od monoline stroke font family, bold cut with $88.93 \%$. Then follows brush stroke font family, semi bold cut with $88.44 \%$, bold stroke font family, semi bold cut with $87.12 \%$, and alternating stroke font family, bold cut with $84.88 \%$.

The lowest accuracy score is achieved by the sets of alternating stroke family, thin cut with $82.89 \%$, than brush stroke, ultra-bold cut with $84.49 \%$, bold stroke font family, ultra-bold cut with $85.03 \%$, and lastly monoline stroke family, ultra-light cut with $87.02 \%$.

Table 6 represents the results of testing of second subgroup of four font families with linked letter characters in seven different letter cuts by AI driven OCR. Here the highest accuracy score is achieved by the sets of brush stroke font family, semi-bold cut with $97.92 \%$. Then follows monoline stroke font family, ultra-light cut with $96.43 \%$, alternating stroke font family, bold cut with $96.13 \%$, and bold stroke font family, semi-bold cut with $95.02 \%$. 
The lowest accuracy score is achieved by the sets of alternating stroke family, thin cut with $92.41 \%$, than bold stroke, ultra-bold cut with $93.02 \%$, brush stroke font family, also ultra-bold cut with $94.07 \%$, and finally monoline stroke family, bold cut with $95.21 \%$.

Table 5: Accuracy results for linked handwritten letter characters in percentage, standard OCR

\begin{tabular}{|c|c|c|c|c|c|}
\hline $\begin{array}{l}\text { Training EMNIST } \\
\text { dataset }\end{array}$ & $\begin{array}{l}\text { Expanded Testing } \\
\text { Dataset }\end{array}$ & $\begin{array}{l}\text { Bold stroke } \\
\text { (linked } \\
\text { characters) }\end{array}$ & $\begin{array}{l}\text { Alternating } \\
\text { stroke (linked } \\
\text { characters) }\end{array}$ & $\begin{array}{c}\text { Monoline } \\
\text { stroke (linked } \\
\text { characters) }\end{array}$ & $\begin{array}{c}\text { Brush stroke } \\
\text { (linked } \\
\text { characters) }\end{array}$ \\
\hline $\begin{array}{l}\text { Digital } \\
\text { handwritten font }\end{array}$ & $\begin{array}{l}\text { Sets of thin cut } \\
\text { Digital handwritten } \\
\text { font }\end{array}$ & $\begin{array}{l}85.28 \\
96.47\end{array}$ & $\begin{array}{l}82.89 \\
96.97\end{array}$ & $\begin{array}{l}87.93 \\
96.51\end{array}$ & $\begin{array}{l}86.49 \\
97.61\end{array}$ \\
\hline $\begin{array}{l}\text { Digital } \\
\text { handwritten font }\end{array}$ & $\begin{array}{l}\text { Sets of ultra-light cut } \\
\text { Digital handwritten } \\
\text { font }\end{array}$ & $\begin{array}{l}85.39 \\
97.89\end{array}$ & $\begin{array}{l}83.56 \\
97.51\end{array}$ & $\begin{array}{l}87.02 \\
97.02\end{array}$ & $\begin{array}{l}86.63 \\
95.58\end{array}$ \\
\hline $\begin{array}{l}\text { Digital } \\
\text { handwritten font }\end{array}$ & $\begin{array}{l}\text { Sets of light cut } \\
\text { Digital handwritten } \\
\text { font }\end{array}$ & $\begin{array}{l}86.21 \\
97.58\end{array}$ & $\begin{array}{l}83.92 \\
97.87\end{array}$ & $\begin{array}{l}87.48 \\
97.74\end{array}$ & $\begin{array}{l}86.02 \\
96.03\end{array}$ \\
\hline $\begin{array}{l}\text { Digital } \\
\text { handwritten font }\end{array}$ & $\begin{array}{l}\text { Sets of regular cut } \\
\text { Digital handwritten } \\
\text { font }\end{array}$ & $\begin{array}{l}86.93 \\
98.73\end{array}$ & $\begin{array}{l}84.53 \\
98.46\end{array}$ & $\begin{array}{l}88.22 \\
98.29\end{array}$ & $\begin{array}{l}87.91 \\
97.44\end{array}$ \\
\hline $\begin{array}{l}\text { Digital } \\
\text { handwritten font }\end{array}$ & $\begin{array}{l}\text { Sets of semi-bold cut } \\
\text { Digital handwritten } \\
\text { font }\end{array}$ & $\begin{array}{l}87.12 \\
97.91\end{array}$ & $\begin{array}{l}84.51 \\
97.98\end{array}$ & $\begin{array}{l}88.01 \\
98.03\end{array}$ & $\begin{array}{l}88.44 \\
98.23\end{array}$ \\
\hline $\begin{array}{l}\text { Digital } \\
\text { handwritten font }\end{array}$ & $\begin{array}{l}\text { Sets of bold cut } \\
\text { Digital handwritten } \\
\text { font }\end{array}$ & $\begin{array}{l}86.49 \\
96.25\end{array}$ & $\begin{array}{l}84.88 \\
96.41\end{array}$ & $\begin{array}{l}88.93 \\
98.66\end{array}$ & $\begin{array}{l}85.93 \\
95.78\end{array}$ \\
\hline $\begin{array}{l}\text { Digital } \\
\text { handwritten font }\end{array}$ & $\begin{array}{l}\text { Sets of ultra-bold cut } \\
\text { Digital handwritten } \\
\text { font }\end{array}$ & $\begin{array}{l}85.03 \\
96.98\end{array}$ & $\begin{array}{l}83.98 \\
96.22\end{array}$ & $\begin{array}{l}87.87 \\
97.01\end{array}$ & $\begin{array}{l}84.49 \\
95.04\end{array}$ \\
\hline
\end{tabular}

Table 6: Accuracy results for linked handwritten letter characters in percentage, Al driven OCR

\begin{tabular}{|c|c|c|c|c|c|}
\hline $\begin{array}{l}\text { Training EMNIST } \\
\text { dataset }\end{array}$ & $\begin{array}{l}\text { Expanded Testing } \\
\text { Dataset }\end{array}$ & $\begin{array}{l}\text { Bold stroke } \\
\text { (linked } \\
\text { characters) }\end{array}$ & $\begin{array}{l}\text { Alternating } \\
\text { stroke (linked } \\
\text { characters) }\end{array}$ & $\begin{array}{c}\text { Monoline } \\
\text { stroke (linked } \\
\text { characters) }\end{array}$ & $\begin{array}{l}\text { Brush stroke } \\
\text { (linked } \\
\text { characters) }\end{array}$ \\
\hline $\begin{array}{l}\text { Digital } \\
\text { handwritten font }\end{array}$ & $\begin{array}{l}\text { Sets of thin cut } \\
\text { Digital handwritten } \\
\text { font }\end{array}$ & $\begin{array}{l}93.22 \\
96.47\end{array}$ & $\begin{array}{l}92.41 \\
96.97\end{array}$ & $\begin{array}{l}93.19 \\
96.51\end{array}$ & $\begin{array}{l}94.42 \\
97.61\end{array}$ \\
\hline $\begin{array}{l}\text { Digital } \\
\text { handwritten font }\end{array}$ & $\begin{array}{l}\text { Sets of ultra-light cut } \\
\text { Digital handwritten } \\
\text { font }\end{array}$ & $\begin{array}{l}93.97 \\
97.89\end{array}$ & $\begin{array}{l}93.63 \\
97.51\end{array}$ & $\begin{array}{l}96.43 \\
97.02\end{array}$ & $\begin{array}{l}96.29 \\
95.58\end{array}$ \\
\hline $\begin{array}{l}\text { Digital } \\
\text { handwritten font }\end{array}$ & $\begin{array}{l}\text { Sets of light cut } \\
\text { Digital handwritten } \\
\text { font }\end{array}$ & $\begin{array}{l}93.46 \\
97.58\end{array}$ & $\begin{array}{l}94.06 \\
97.87\end{array}$ & $\begin{array}{l}96.29 \\
97.74\end{array}$ & $\begin{array}{l}97.71 \\
96.03\end{array}$ \\
\hline $\begin{array}{l}\text { Digital } \\
\text { handwritten font }\end{array}$ & $\begin{array}{l}\text { Sets of regular cut } \\
\text { Digital handwritten } \\
\text { font }\end{array}$ & $\begin{array}{l}95.83 \\
98.73\end{array}$ & $\begin{array}{l}95.43 \\
98.46\end{array}$ & $\begin{array}{l}96.17 \\
98.29\end{array}$ & $\begin{array}{l}97.62 \\
97.44\end{array}$ \\
\hline $\begin{array}{l}\text { Digital } \\
\text { handwritten font }\end{array}$ & $\begin{array}{l}\text { Sets of semi-bold cut } \\
\text { Digital handwritten } \\
\text { font }\end{array}$ & $\begin{array}{l}95.02 \\
97.91\end{array}$ & $\begin{array}{l}95.99 \\
97.98\end{array}$ & $\begin{array}{l}95.87 \\
98.03\end{array}$ & $\begin{array}{l}97.92 \\
98.23\end{array}$ \\
\hline $\begin{array}{l}\text { Digital } \\
\text { handwritten font }\end{array}$ & $\begin{array}{l}\text { Sets of bold cut } \\
\text { Digital handwritten } \\
\text { font }\end{array}$ & $\begin{array}{l}93.29 \\
96.25\end{array}$ & $\begin{array}{l}96.13 \\
96.41\end{array}$ & $\begin{array}{l}95.21 \\
95.66\end{array}$ & $\begin{array}{l}94.93 \\
95.78\end{array}$ \\
\hline $\begin{array}{l}\text { Digital } \\
\text { handwritten font }\end{array}$ & $\begin{array}{l}\text { Sets of ultra-bold cut } \\
\text { Digital handwritten } \\
\text { font }\end{array}$ & $\begin{array}{l}93.02 \\
96.98\end{array}$ & $\begin{array}{l}93.17 \\
96.22\end{array}$ & $\begin{array}{l}95.73 \\
97.01\end{array}$ & $\begin{array}{l}94.07 \\
95.04\end{array}$ \\
\hline
\end{tabular}

Figure 5 shows average percentage increase in recognizability of linked handwritten letter characters using Al driven OCR compared to standard OCR. The biggest increasing rate is for alternating stroke font family 
and amounts $10.36 \%$. The smallest increasing is noted for monoline stroke font family, $7.63 \%$. Bold stroke font family records an increase rate of $7.91 \%$, and brush stroke font family of $9.58 \%$. Average percentage for subgroup of independent handwritten characters is $8.87 \%$.

Individually speaking it is $5.26 \%$ for monoline stroke font family, thin cut, and $11.36 \%$ for brush stroke font family set, light cut.

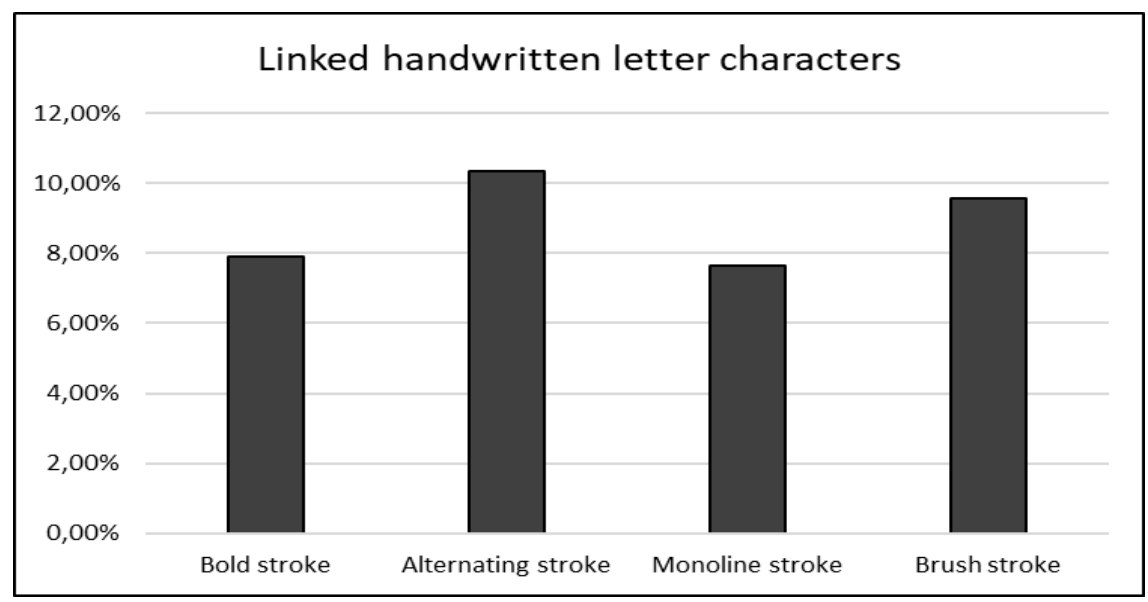

Figure 5: Average percentage increase in recognizability of linked handwritten letter characters using Al driven OCR

An increase in all values was observed, which means that the application of Al driven OCR increased the recognizability of the characters in the sample.

The increase in recognizability using Al driven OCR was expected to bi higher in the subgroup of linked handwritten letter characters because the initial results were lower for this subgroup when using standard OCR.

Analysis of the samples determined that they were deviations are the most pronounced in words with two or more ascenders $(k, b, l, d, h, t)$ and descenders $(g, j, p, q, y)$. If the letter characters are linked by ligatures, the ascending and descending strokes are even less recognizable to the scanners.

In subgroup of independent letter characters, errors were observed in similar rounded lines such as the letter characters $a$, and $e$. In the subgroup of letter characters connected by ligatures, errors were also observed in similar rounded lines such as the letter characters a and e, $m$ and $n$, but also in ascenders $b$ and $\mathrm{I}$, and descenders $\mathrm{g}$ and $\mathrm{q}$.

Here results are based on a small number of tested samples. In future work can be extend to a larger batch pool and for other specific letter characters, and numbers as well. Because OCR is very sensitive, and any disorder can easily confuse similar letter characters it would be good to make software distortion of letter characters in order to increase the number of letter characters and different variations in the database.

Reducing the number of deviations shows that the neural network gives acceptable answers but requires creation of a larger database within about 56,000 different letter characters.

\section{CONCLUSIONS}

Handwritten documents are increasingly being digitized. Therefore, it is important that the base of fonts and individual letter characters be as large as possible. For this purpose, it is useful to create as many digital handwriting fonts as possible. Artificial intelligence helps in the process of identification and classification within a complex database of fonts. This paper describes the application of Al driven OCR based on MLP (Multilayer Perceptron) BPNN (Back Propagation Network) algorithm.

Non-linear increase of $5.70 \%$ for the subgroup of fonts with unrelated characters, and $8.87 \%$ for the subgroup of fonts with ligatures associated with characters. It is therefore indicative of the development of Al driven OCR.

Also, experiment indicates that original the EMNIST dataset could be improved adding a new letter character sets which enable to neural networks for recognition to be more accurate.

There are several areas for future work. The results need to be verified with extended dataset and different kind of algorithm. 


\section{REFERENCES}

[1] Cohen, G., Afshar, S., Tapson, J., van Schaik, A.: "EMNIST: an extension of MNIST to handwritten letters", URL: http://arxiv.org/abs/1702.05373 (last request: 2020-07-13).

[2] Desai, P. A., Bhavikatti, S. N., Patil, R.: "Design and Simulation of Handwritten Text Recognition System", International Journal of Current Engineering and Technology 1, 259-262, 2013.

[3] Driss, S. B., Soua, M., Kachouri, R., Akil, M.: "A comparison study between MLP and Convolutional Neural Network models for character recognition", Proceedings of SPIE Conference on Real-Time Image and Video Processing 2017, (SPIE: Anaheim, California, 2017), pages 1-12.

[4] D’Souza, L., Mascarenhas, M.: “Offline Handwritten Mathematical Expression Recognition using Convolutional Neural Network", Proceedings of International Conference on Information, Communication, Engineering and Technology 2018, (ICICET: Narhe, Pune, India, 2018), pages 1-3.

[5] Grzelak, D., Podlaski, K., Wiatrowski, G.: "Analyze the effectiveness of an algorithm for identifying Polish characters in handwritting based on neural machine learning technologies", Journal of King Saud University - Computer and Information Sciences 08 (1-7), 2019. doi: https://doi.org/10.1016/j.jksuci.2019.08.001.

[6] Jafri, R., Arabnia, H. R.: "A Survey of Face Recognition Techniques", Journal of Information Processing Systems 5 (2), 41-68, 2009. doi: https://doi.org/10.1016/j.jksuci.2019.08.001.

[7] Maitra, D. S., Bhattacharya, U., Parui, K.: "CNN Based Common Approcah to Handwritten Character Recognition of Multiple Scripts", Proceedings of $13^{\text {th }}$ International Conference on Document Analysis and Recognition 2015, (ICDAR: Tunis, Tunisia, 2015), pages 1021-1025.

[8] [8] Phangtriastu, M. R., Harefa, J., Tanoto, D. F.; "Comparison between neural network and support vector machine in optical character recognition", Proceedings of $2^{\text {nd }}$ International Conference on Computer and Computational Intelligence 2017, (ICCSCI: Bali, Indonesia, 2017), pages 351-357.

[9] Rao, N. V., Sastry, A. S. C. S., Chakravarthy, A. S. N., Kalyanchakravarthi, P.: “Optical Character Recognition Technique Algorithms", Journal of Theoretical and Applied Information Technology 83 (2), 275-282, 2016.

[10] Zheng, Y., Iwana, B. K., Uchida, S.: "Mining the Displacement of Max-pooling for Text recognition", Pattern Recognition 93, 558-569, 2019. doi: 10.1016/j.patcog.2019.05.014.

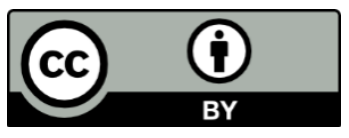

(C) 2020 Authors. Published by the University of Novi Sad, Faculty of Technical Sciences, Department of Graphic Engineering and Design. This article is an open access article distributed under the terms and conditions of the Creative Commons Attribution license 3.0 Serbia (http://creativecommons.org/licenses/by/3.0/rs/). 